\title{
Silencios y repeticiones de la violencia en Colombia. La novela histórica como ontología crítica del presente
}

\section{Silences and Repetitions of Violence in Colombia. The Historical Novel as an Ontological Criticism of the Present}

\begin{abstract}
Resumen
Este trabajo aborda el oficio autoral de la novela histórica contemporánea como una práctica que permite configurar una ontología crítica del presente, es decir, un campo de reflexión que indaga por el estatuto ontológico de la actualidad. En el caso colombiano, la ficción histórica se ha interesado por interpretar estéticamente el pasado de las violencias y del conflicto armado como mecanismo para comprender el devenir del presente. Este ensayo propone que las novelas históricas, aunque se ubiquen en un espacio-tiempo ya transitado, mantienen su matriz de sentido anclada a la interpelación de la realidad vigente. Para tal fin, se analizan las novelas El Crimen del siglo (2006) de Miguel Torres y Tanta sangre vista (2007) de Rafael Baena.
\end{abstract}

Palabras claves

Literatura, novela, ontología, violencia.

\begin{abstract}
This paper addresses the contemporary historical novel as a practice of critical ontology of the present. That is to say, a field of reflection that investigates the current ontological status. In the Colombian case, historical fiction has been attentive to interpret the past of violence and armed conflict in an aesthetic way as a mechanism to understand the future of the present. This essay proposes that historical novels, despite being located in a space-time already travelled, maintain a matrix of meaning anchored in the present reality's interpellation. To
\end{abstract}


this end, this paper analyzes the novels El crimen del siglo (2006) by Miguel Torres and Tanta sangre vista (2007) by Rafael Baena.

Keywords

literature, novel, ontology, violence.

\author{
Frágiles \\ son las verdades \\ que sostienen la realidad. \\ El mundo mismo \\ está en equilibrio \\ sobre imaginarios \\ quizá crueles \\ ojalá virtuosos. \\ Una puerta separa \\ dos mundos luminosos \\ ¿Cómo vivir \\ sin esa puerta? \\ Esther Pardo. Cordura.
}

\section{Introducción}

¿Se puede escindir el cuerpo que escribe de aquello sobre lo que escribe? ¿El lugar del cuerpo desaparece en la escritura mediante artificios como la ficción novelesca? ¿O acaso es inevitable que el rastro de la voluntad y el peso de la circunstancia del autor habiten en el texto literario? Si el escritor pretende suplantarse hasta diluirse y desaparecer en otras voces, entonces sólo quedaría de él un espectro inasible y una imagen de sí que ya no le pertenece. Sin embargo, es posible que el cuerpo de quien escribe persista en aferrarse a lo enunciado y en dejar algún vestigio de su identidad. Si se acepta esto último, el lugar de enunciación -que es siempre la experiencia de un presente- se resiste a huir para evaporarse subrepticia y sutilmente en el texto como un eco indeleble. La relación entre el presente, que posibilita la escritura, y el texto literario que resulta de ella conduce a realizar análisis literarios que reconozcan, como lo sugiere Pedro Gómez Valderrama (1989), que "el escritor vive en sus obras" (Gómez 14). Así, en la 
imaginación literaria la realidad de la circunstancia vital del escritor es re-creada y puesta en tensión para mostrar sus fracturas, sus vacíos y silencios, lo que da lugar a la imagen de un presente reducido a una quebradiza y frágil posibilidad.

Este artículo propone un diálogo entre la ontología crítica y la novela histórica colombiana que hace posible desnaturalizar el presente. La "desnaturalización" es la negación de alguna esencia o propiedad trascendental de aquello que se desea analizar. De ahí que el presente no sea comprendido como el resultado inevitable del thelos de la historia, sino como un segmento contingente, difuso, arbitrario y finito, producido por la turbulencia de fuerzas históricas. El presente o la actualidad es una matriz heterogénea compuesta por una multiplicidad de relaciones de saber/poder que están en permanente tensión. La desnaturalización percibe el presente como una posibilidad, cuyo estatuto ontológico es abierto y susceptible de ser redireccionado (Foucault Microfisica 7-29).

En el caso colombiano, el estatuto ontológico de su actualidad está atravesado por las dinámicas del fenómeno sociohistórico de sus violencias y los efectos del Conflicto Armado Interno. Las prácticas de violencia se han impuesto en los colombianos como un ethos colectivo, a través de significados restringidos y excluyentes de la vida en común que han impedido el "acontecimiento político", es decir, la realización del "horizonte abierto, inescrutable e impredecible" (Cadahia 65) propio de un sistema democrático. A pesar de la firma del Acuerdo Final de Paz en noviembre de 2016 entre el Estado colombiano y la guerrilla de las FARC $^{1}$, en los años recientes la sociedad colombiana ha experimentado un escalamiento de prácticas de violencia ${ }^{2}$ inscritas en cuerpos y comunidades ${ }^{3}$. Las

1 Tras más de 50 años de confrontación y varios procesos de paz fallidos, se da fin al Conflicto Armado entre la insurgencia de las Fuerzas Armadas Revolucionarias de Colombia FARC-EP y el Estado Colombiano a través de la firma del texto del "Acuerdo final para la terminación del conflicto y la construcción de una paz estable y duradero" el 24 de noviembre de 2016. Ver: http://www.altocomisionadoparalapaz.gov.co.

2 El informe del Instituto de estudios para el desarrollo y la paz con corte al 23 de agosto, afirma que " 182 personas han sido asesinadas en 44 masacres cometidas en lo corrido del 2020" (Indepaz 7)

3 La violencia, en tanto práctica que altera la dimensión sensible de la experiencia humana, se inscribe en el cuerpo humano. Es una acción - de violentar el cuerpo de otro- que tiene en la materialidad corporal su condición de posibilidad. La violencia se sitúa en el orden de la 
causas, relaciones e impactos de esta realidad han sido ampliamente estudiadas en investigaciones interdisciplinarias de larga duración ${ }^{4}$ que han consolidado un campo de estudios sobre el tema, conocido como la "violentología" (Cartagena 8$15)$.

Por otra parte, la tradición literaria del país, en tanto práctica social y producto cultural, se ha mantenido atenta a este horizonte, hasta posicionar la violencia como un gran "monotema". La novela de y sobre la violencia en Colombia ha sido un artefacto interpretativo y transfigurador del fenómeno sociohistórico que, mediante la ampliación estética de los niveles de realidad, ha convertido a la violencia en un "objeto estético" (Padilla 23). La intervención de la novela colombiana en la turbulencia producida por la violencia se demuestra en la extensa producción desde mediados de la década de los 40 del siglo XX, cuando la dinámica del conflicto se inserta en la realidad nacional. Estas novelas se inscriben bajo el rótulo de "novela [de] y [sobre] la violencia" (Osorio 97-100). A su vez, György Lukács (1964) recuerda que la novela histórica suele confrontarse con la historia desdoblando literariamente periodos caracterizados por traumas sociales, por lo que parece inevitable hallar en la violencia posibilidades narrativas para la novela histórica. Esto ocurre con novelas como La marquesa de Yolombó (1928) de Tomás Carrasquilla, La casa grande (1962) de Álvaro Cepeda Samudio o Amores sin tregua (2006) de María Cristina Restrepo, en donde los escritores han buscado comprender literariamente la violencia de su tiempo acudiendo a recrear pasados no menos violentos (Montoya ix-Xvi).

Ahora bien, el uso de la crítica ontológica en el campo literario está limitada por la verosimilitud y la proyección narrativa de la experiencia, por cuanto los cuerpos -individuales y sociales- y los cronotopos se desarrollan en la esfera

experiencia (epistémica, simbólica, cultural, etc.) y en las relaciones históricas que tienen lugar en la matriz de saber/poder. (Caponetto 2004; Bonilla 2010; Falconí 2011).

4 Destacan los trabajos Sánchez y Peñaranda (1986/2015), Bolívar y Vásquez T (2003) y Zuleta (2011). Otros trabajos más recientes son el informe Basta Ya, publicado en 2013 por el Centro Nacional de Memoria Histórica (CNMH) y el informe Contribución al entendimiento del conflicto armado en Colombia, escrito por la Comisión Histórica del Conflicto y sus Víctimas en 2015, en el marco de los diálogos de Paz de La Habana entre el gobierno y la guerrilla de las FARC. 
diegética construida por el autor y no en la esfera archivística del genealogista. No obstante, este diálogo entre la literatura y la filosofía pretende subvertir la consideración de la novela histórica como un género escapista de los conflictos o antagonismos sociales (Menton 51). A contrapelo, se busca posicionar sus anacronías -pensar el pasado desde el presente- como pliegues de sentido críticos que erosionan la solidez del presente (Montoya xii). Lo anterior no debe perder de vista que en el análisis estético de la ficción histórica es necesario privilegiar la capacidad interpretativa de la creación literaria sobre la búsqueda de mimesis de la obra literaria con el hecho social ${ }^{5}$.

Este ensayo propone que las novelas históricas, aunque se ubiquen en un espacio-tiempo ya transitado, mantienen su matriz de sentido anclada a la interpelación de la realidad vigente. El texto tiene como objetivo realizar un ejercicio hermenéutico que indague por aquellos marcadores narrativos implícitos en dos obras literarias que, según la perspectiva expuesta, actúan como una crítica de la actualidad colombiana. Para ello, se dialoga con las novelas El crimen del siglo (2006) de Miguel Torres y Tanta sangre vista (2007) de Rafael Baena. La primera novela pone el foco en uno de los acontecimientos más emblemáticos de la historia nacional, como es el Bogotazo, hecho sucedido el 9 de abril de 1948; la segunda compone una atopía narrativa que cuestiona los cimientos del proyecto republicano en la segunda mitad del siglo XIX. Los autores buscan comprender las fisuras o grietas de su presente, a partir de la re-creación e invención del pasado ${ }^{6}$ y de las múltiples violencias que han configurado el presente del conflicto

5 Iván Padilla (2017) se pregunta “itoda la literatura colombiana se relaciona con la violencia? Sin duda, pero ¿debe ser abordada con categorías no estéticas? ¿debe prevalecer la perspectiva temática en su análisis?" (49). El crítico y académico cuestiona la "comodidad" que conlleva agrupar toda producción literaria bajo el rotulo "sobre" o "de" la violencia en las obras literarias. En su criterio, la crítica de la novela colombiana debe identificar "el tipo de solución estética que los escritores descubren o proponen en el momento que se confrontan con la Historia" (55) (la cursiva es mía).

6 Otras novelas históricas contemporáneas que comparten el mismo interés son: La ceiba de la memoria (2007) de Roberto Burgos Cantor, El ruido de las cosas al caer (2011) y La forma de las ruinas (2015) de Juan Gabriel Vásquez, Los derrotados (2012) y Tríptico de la infamia (2014) de Pablo Montoya, y Rebelión de los oficios inútiles (2014) y El año del sol negro (2018) de Daniel Ferreira, entre otros. 
colombiano. Se concluye que los marcadores narrativos, mediante los cuales se ejerce la praxis crítica, pueden ser leídos como formas de inmunización del poder que ha gobernado y moldeado la historia colombiana.

\section{Rastreando las figuras autoriales: la ontología de sí como práctica de libertad}

La ontología crítica implica una actitud escéptica sobre la inevitabilidad de lo real y expresa una forma de subjetivación política que abre la "posibilidad de constituirnos a nosotros mismos como sujetos de nuestras acciones" (Martínez 17). La alusión directa de lo que es la ontología crítica del presente aparece con Michael Foucault en su ensayo ¿Qué es la Ilustración? (1991), donde analiza el texto homónimo escrito por Inmanuel Kant en 1784. El pensador francés concluye que la actualidad que se vive es el referente y punto de partida de la reflexión filosófica crítica. La ontología crítica germina con la pregunta del sujeto por $s u$ presente: ¿Por qué soy lo que soy, y no soy de otra forma? Dicha interpelación ofrece un camino a la subjetividad para salir de sí y comprenderse en una matriz de sentido más amplia, lo que pluraliza el cuestionamiento: ¿Por qué somos lo que somos? o ¿Qué ha hecho que seamos aquello que somos y no otros?

La cuestión que a mi juicio surge por primera vez en este texto de Kant es la cuestión del presente, la cuestión de la actualidad: ¿Qué es lo que ocurre hoy?, ¿Qué es lo que pasa ahora?, ¿Qué es ese "ahora” en el interior del cual estamos unos y otros y que define el momento en el que escribo? [...] La cuestión se centra en lo que es este presente, trata en primer lugar sobre la determinación de un cierto elemento del presente al que hay que reconocer, distinguir, descifrar de entre los otros. ¿Qué es lo que en el presente tiene sentido para una reflexión filosófica? (Foucault, ¿Qué es la ilustración? 198)

De esta forma, la actualidad que configura la experiencia vital del autor funciona como proto-posibilidad de la escritura, es el terreno propio de la existencia 
y la condición de posibilidad para dar cuenta de uno mismo (Butler 13-48). Por otra parte, el autor es una corporalidad y subjetividad performativa expuesta públicamente a través de su obra o corpus, una metáfora "que agrupa orgánicamente una colección de textos dispersos [...] vinculad[a] a su vez a un individuo, cuyos procesos de subjetivación y hasta de corporalización tendrán lugar de manera indisociable con su rol autorial, que marca un modo de existencia" (Torras 23). De este modo, el autor de novelas históricas interroga los acontecimientos y simultáneamente se pregunta por sí mismo. El autor conjuga el pasado sobre el que escribe y el presente en el que vive para entrelazar las dos temporalidades y disolverlas simbióticamente en la narrativa ficcional de la novela histórica.

El primer autor al que hace referencia el presente texto es Miguel Torres (1942), novelista, cuentista y uno de los dramaturgos más reconocidos de Colombia. Se trata de un autor que penetra artísticamente en los eventos históricos de la violencia y el conflicto armado. En 1994 se estrenó su obra teatral La siempreviva, catalogada como una de las cinco piezas más importantes del teatro colombiano, y adaptada al cine en el año 2015. La obra gira en torno a la desaparición de una mujer durante la toma del Palacio de Justicia en Bogotá protagonizada el 6 de noviembre de 1985 por la guerrilla del M-19, y se enfoca en el drama que dicho suceso tiene en su entorno familiar. La pieza teatral hace un homenaje a las personas desaparecidas a manos de las fuerzas militares durante la llamada "retoma del palacio", cuya telúrica imagen es la de un tanque de guerra del ejército destrozando la puerta del edificio.

En el 2006 publica la novela El crimen del siglo, adaptada al teatro en el año 2018. Es la primera novela de la trilogía que se ocupa del magnicidio del político liberal, abogado y líder popular Jorge Eliecer Gaitán ocurrido el 9 de abril de 1948 en el corazón de la capital colombiana. Las consecuencias inmediatas de este hecho se conocerán con el nombre del "Bogotazo", piedra angular del Conflicto Armado Interno surgido en la segunda mitad del siglo XX, hasta la actualidad. Más tarde publica El incendio de abril (2012), obra centrada en el 
impacto del Bogotazo sobre la multitud anónima, y La invención del pasado (2015), metaficción que tiene como hilo narrativo una historia familiar. Esta "trilogía del 9 de abril" configura un universo narrativo que suspende el estatuto de verdad de los acontecimientos para dar paso a un diseño ficcional de la memoria.

Miguel Torres sitúa en Bogotá las experiencias de los personajes que protagonizan sus novelas. Se apoya en una cartografía urbana multidimensional, algo así como un continuo deja-vú que pasa en distintas épocas, por las mismas calles, los mismos cafés, donde se proyectan las mismas películas y suenan los mismos boleros en cada novela. La ciudad es un escenario vivo que participa de los diálogos con los carteles pegados en sus paredes, los titulares de prensa y los avisos del tranvía y autobuses. El contexto narrativo de sus personajes es un ejercicio de recuperación de la propia memoria del autor. Bogotá es cómplice de sus artificios y le permite desdoblar poéticamente una historia agrietada e inestable. Para Miguel Torres, la Historia oficial -discurso sedimentado del pasado- está plagada de puntos negros, de lugares que no fueron observados y que carecen de narración. Estas opacidades del relato histórico devienen en posibilidades narrativas. Por eso afirma que "a donde no llega la historia, llega la literatura", no para darle una Verdad a aquello despojado de narración, sino para "inventar el pasado" (Torres, Comunicación personal, sept. 2020).

El presente es, desde su perspectiva, una edificación incompleta, una imagen difusa que se ha hecho sólida a través de las prácticas de violencia. El presente, en vez de exponerse como el resultado natural de lo acontecido, es una ilusión creada sobre ocultamientos del pasado que ofrecen -paradójicamenteseguridad ontológica para la sociedad y la perpetuación de la racionalidad del aparato estatal:

[...] aquí ha pasado una cosa muy paradójica, es que, por ejemplo, el crimen de Gaitán quedó realmente en la oscuridad y eso el Estado siempre lo siguió haciendo, tapando u ocultando la realidad, sobre todo las cosas en que el Estado tiene culpa. Ha ocultado siempre en lo posible esas 
verdades. Y paradójicamente la gente no quiere saber nada de eso. (Torres, Comunicación personal, dic. 2018)

Profundizar en el asesinato de Gaitán y sus ocultamientos históricos mediante la trilogía del 9 de abril lleva a Torres a encontrarse con la función orgánica del Estado en lo sucedido. No obstante, su imaginación literaria se resiste a hacer una crítica explícita a la violencia de Estado y una lectura jerárquica del poder. La dimensión política de la novela es enunciada en metáforas insertas en las experiencias de los personajes y la relación que tienen con el mundo, lo que le permite abordar dramas universales como el dolor, la soledad y la impunidad, sin buscar condenas o redenciones.

El segundo autor al que este texto hace referencia es el periodista, fotógrafo y novelista Rafael Baena (1956-2015). Nació en Sincelejo en 1956 y falleció en Bogotá en el 2015, tras quedarse sin aire, después de los cientos de cigarrillos que quemó durante su vida. Como periodista conoció los conflictos armados que azotaron Centroamérica durante los años 80 y atravesó la geografía colombiana para sentir de cerca la guerra del país. Concebía su oficio como una actividad que hace sudar y que produce miedo, por lo que admiraba a Robert Kappa y Ryszard Kapuscinski, y reprochaba el periodismo de escritorio. Con los años se le volvió tedioso cubrir guerras y conflictos protagonizados por generales, políticos o subversivos. Baena fue un testimonio vivo de la guerra en Colombia, cuya persistencia le había producido, en palabras del autor:

Una especie de hastío a todo lo que fuera uniformes y armas y todo lo que al principio me seducía, terminó por convertirse en algo desagradable para mí [...] los señores de la guerra son los señores de la guerra, los extremos del anillo se tocan, la serpiente se muerde la cola, llámalo como quieras. De pronto es una visión un poco cínica, pero es la visión de un reportero cansado. (Baena, Entrevista, ene. 2014) 
Se hizo escritor de novelas históricas a los 51 años de edad con la publicación de Tanta sangre vista (2007), un intento de respuesta a la constante pregunta que sus hijos le planteaban sobre el: “¿Por qué? ¿Por qué esto que estamos viviendo?", a lo que él comentaba: "yo me sentía obligado a responder, pero no tenía cómo explicarles, y que no les quitara las ganas de vivir" (Baena, Rafael. Entrevista, ene. 2014). Posteriormente publicó ;Vuelvan caras, carajo! (2009), donde le sigue la pista a Juan José Rondón, figura marginal de la campaña libertadora durante la independencia. Vendría después La bala vendida (2011), una historia familiar arrollada por la guerra y la locura, y La guerra perdida del indio Lorenzo (2015), centrada en Victoriano Lorenzo, único general indígena del ejército liberal en la defensa de Panamá. Esta dos últimas novelas se ambientan en La Guerra de los Mil Días (1899-1902). Todas ellas conforman una tetralogía de la guerra en Colombia durante el siglo XIX.

En su interés por buscar las raíces de la violencia que rodean su presente, Baena vuelve a la centuria de la independencia, época que ensambló el proyecto republicano y estableció los cimientos del Estado-nación. Su predilección por la era decimonónica produce un escenario narrativo dominado por la estética de la vida rural y contextos de trochas, haciendas, montañas, campesinos y caballos. A contracorriente de la moda literaria de la novela urbana y experimental, Baena posiciona sus anacronías con el protagonismo del campesinado y los equinos, a quienes les dedicó, con profunda admiración, un ensayo titulado Ciertas personas de cuatro patas (2014). La guerra del siglo XX también fue su motivo literario con Siempre fue ahora o nunca (2014), novela sobre la violencia del conflicto armado en la segunda mitad del siglo XX. El autor no se interesa por exaltar próceres o héroes, pues considera que a estos personajes monumentales es mejor "no pararles tantas bolas, ya tienen estatuas y todo, que no jodan más. Sí es que por tanto caudillismo es que estamos tan jodidos". Y recalca la atención que merece "la gente que va a la guerra, gente que en últimas, si pudiera escoger, no iría; que es gente como uno" (Baena, Entrevista, ago. 2010). 
El gesto político de sus novelas reside en desnudar los motivos de la guerra, entendida como un dispositivo de gobierno que ha garantizado el ordenamiento institucional del país (Pérez 37-83). Para el autor, el pasado y el presente se solapan en este dispositivo que, aunque modifique sus técnicas de muerte y el nombre de sus verdugos con el pasar del tiempo, sigue siendo el mismo. Más que un continuum inmóvil, como pareciera ser, su comprensión del tiempo es la de un Uróboro, figura que sirve para explicar la persistencia histórica de la guerra. Desde su perspectiva, la constancia de guerra es la prueba del desmoronamiento de la ilusión del progreso que dominó el mito nacional en el siglo XIX, hasta hoy, y alimenta su sospecha frente a la supuesta novedad de la violencia actual que, a decir suyo "no es tan reciente, sino muy antigua" (Baena, Entrevista, ago. 2011).

Miguel Torres y Rafael Baena han sido subjetivados por el horizonte de las violencias históricas de la sociedad colombiana, cuya hegemonía la ha tenido el Conflicto Social y Armado, desde los años 60 del siglo XX, hasta la actualidad. Sus creaciones literarias permiten una ficcionalización sensible del pasado a través de personajes que experimentan un sentido trágico producto de la configuración de la nación. Por un lado, El crimen del siglo sitúa el foco de atención en la experiencia del presunto asesino de Gaitán, Juan Roa Sierra, chivo expiatorio que representa la figura de un sacrificado necesario, un homo sacer que permite la continuación del statu quo y que anticipa el conflicto armado actual. Por otro lado, en Tanta sangre vista plantea una travesía por las guerras civiles del siglo XIX a partir de las frustraciones de Enrique Arce, un guerrero ilustrado condenado a ver permanentemente la guerra y la sangre. Los ocultamientos y opacidades denunciados por Torres y la repetición del pasado revelada por Baena son los marcadores narrativos implícitos que dan cuenta del interés crítico en clave ontológica que representan las novelas. En ambos casos se proyecta difusamente la imagen de un poder que se apoya en la violencia para inmunizarse y cuya pretensión es clausurar y restringir la emergencia de posibilidades emancipatorias. 
CATEDRAL TOMADA: Revista de crítica literaria latinoamericana / Journal of Latin American Literary Criticism Silencios y repeticiones de la violencia en colombia. La novela histórica como ontología crítica del presente

\section{El crimen del siglo y los silencios de la realidad}

La novela El crimen del siglo de Miguel Torres no busca consentir o aprobar relato histórico alguno, sino persigue "inventar el pasado". La obra sitúa a Juan Roa Sierra, "presunto" asesino de Gaitán, como protagonista. En este sentido, es desde la perspectiva del villano o antihéroe que se teje la trama narrativa. La novela está dividida en cuatro partes que, vistas en su totalidad, proyectan una imagen laberíntica, una cartografía permeada por zonas ocultas que se encuentran atravesadas por la vicisitud y el azar. El texto apunta a la reconstrucción del crimen del líder liberal, cruzando múltiples acontecimientos que dejan, a su paso, un resto indescifrable, un silencio abismal y una multitud de cabos sueltos que carecen de narración. La asignación laberíntica es un guiño borgiano, que hace de El crimen del siglo una invitación al enigma de la experiencia estética que trasciende hacia la reflexión filosófica. El laberinto convierte toda enunciación de certeza y respuesta definitiva en una duda perpetua:

Quizá el fin del laberinto -si es que el laberinto tiene un fin-, sea el de estimular nuestra inteligencia, el de hacernos pensar en el misterio, y no en la solución. Es muy raro entender la solución, somos seres humanos, nada más. Quizá los enigmas sean más importantes que las soluciones. (Borges 25)

La novela se separa del afán concluyente y detectivesco por dos razones. En primer lugar, no se interesa por revisar o ficcionalizar los hechos probados del asesinato de Gaitán, como son la hora en que fue asesinado, el número de disparos recibidos o el posterior linchamiento que recibió Juan Roa Sierra. Por el contrario, su pretensión es indagar por los hechos no probados, por aquellos silencios y proscripciones de la historia oficial, que en la novela adoptan distintas formas, sean personajes enigmáticos o intereses ocultos. En segundo lugar, Gaitán y Roa, más allá del significado histórico que guardan sus figuras, aparecen como personajes atrapados y confundidos dentro de un laberinto que terminará con sus vidas. La 
novela se vale de las conmociones sociales cotidianas y de las frustraciones ciudadanas que emergen ante la creciente violencia rural que azota al país. Estas fuerzas se encarnan en la corporalidad de Roa hasta el día de su muerte. El interés por lo indescifrable y la preocupación por lo no dicho ubican la novela en el marco de la posibilidad y en la proyección narrativa de un "doble" (Rosset 9-20) imaginativo de la realidad que se moviliza en el cuerpo de Roa.

La primera parte de la novela se llama "Roa". En ella se moldea una imagen del presunto asesino como hombre desafortunado, símbolo del anonimato, fruto de la pobreza material y expresión de una subjetividad incapaz de encarar la vida. El inestable y depresivo Juan padece de constantes "rachas de pereza tan frecuentes en él, durante las cuales no lo paraba de la cama ni un temblor de tierra" (Torres 21). Es un tipo supersticioso y asomado a la locura. El mismo Roa Sierra comenta que "hay días que oigo voces en mi cabeza, y cuando me miro al espejo tengo la impresión de que mi cara se parece a la del general Santander" (70). En lugar de reconocerse, Roa anula su propia singularidad y se desdobla en otros. Esto le produce una fragilidad ontológica y la sensación de incertidumbre sobre su identidad, de "sospechar que quizás yo no sea algo, sino nada" (Rosset 86). El primer ocultamiento de la novela es la misma vida de Roa y las opacidades que lo habitan.

El inicio de la novela se sitúa horas antes de que el líder liberal sea asesinado. Roa desencadena el drama cuando, agitado y asustado, le dice a su amigo astrólogo que "he sabido, arrancó por fin, y no me pregunte cómo, que hoy piensan asesinar a Jorge Eliecer Gaitán" (15). La presión le da un respiro cuando sentencia "el que va a matarlo soy yo" (16). El laberinto retrocede en el tiempo para explicar el motivo que llevaría a Juan Roa Sierra a asesinar al caudillo liberal, hecho sucedido poco más de un año antes del asesinato. El quiebre se produce cuando el también liberal y gaitanista Juan Roa conoce a su ídolo y modelo a seguir; "Necesito hablar con el doctor Gaitán, le dijo a la secretaria" (17). Roa necesita la ayuda del caudillo y espera una actitud amable por parte de él. Pero cuando se encontraron frente a frente: 
[...] no se atrevió a tenderle la mano para saludarlo. De malas Roa. La primera impresión que le causó a Gaitán fue desafortunada. Al caudillo le disgustó la apariencia de aquel hombre cuya humildad, en extremo servil, alertó su desconfianza. (19)

Lo que sucedió luego cayó como una roca sobre la frágil humanidad de Juan Roa. "Yo no doy ni pido puestos para nadie, no estoy en el poder, respondió Gaitán visiblemente molesto. Así como vino aquí vaya y pídale cacao al gobierno. Ellos sí tienen cómo ayudarlo" (19). Este suceso inocula en Roa el odio y el resentimiento hacia el caudillo liberal.

La segunda parte se llama "La cacería" y desarrolla el plan de Juan Roa (el cazador) para asesinar a Gaitán (la presa), a quien culpa de su miseria. Concluye que asesinar al caudillo es la única forma de reconciliarse con el mundo, su familia y su propia existencia. Como telón de fondo se narra un ambiente político turbulento y se hace referencia a las amenazas diarias "anónimas" que recibía el caudillo liberal. La ruptura de la imagen idílica que tenía Roa de Gaitán y la animadversión que incuba posteriormente hasta decidir asesinarlo se relaciona con la tesis conservadora de que la idiosincrasia "bárbara" y la "ignorancia del pueblo" fueron las principales causas de la violencia en Colombia (Zuleta 14).

Sin embargo, el objetivo del narrador es ironizar esta tesis para mostrar la ingenuidad y oportunismo que conlleva el creer que el pathos de la condición humana puede explicar la complejidad del Conflicto Social y Armado en el país. Para ello se señalan las opacidades que deambulan por el texto, mediante personajes enigmáticos como, por ejemplo, el doctor Urrutia, una figura misteriosa y clave en las desventuras de Juan. El viraje se da en la tercera parte llamada "Las trampas del azar" con la aparición de hombres sospechosos recomendados por Urrutia, para los cuales Juan termina siendo chofer en un trabajo sobre el cuál no podía preguntar y que finalmente no llegó a consumarse. La frase de "mejor no pregunte" convierte a Juan en una marioneta, pues su vida está condicionada al silencio y a la ausencia 
de certezas. La desgracia de Juan llega con los sujetos sin nombre y sin procedencia conocida que lo abordan una noche mientras espía la casa del caudillo.

Son ellos quienes le ordenan que asesine a Gaitán, a lo que Roa manifiesta: "si tantas ganas tienen de matarlo, ¿por qué no lo matan ustedes mismos?, se atrevió a preguntar sin medir el alcance de sus palabras. Por la sencilla razón, dijo el mandamás, de que ya tenemos quién lo haga por nosotros" (49). Juan se convierte en un mensajero de otros, un subordinado sin voluntad que debe asumir la acción y ensuciarse las manos. "Se le van a pagar cinco mil pesos, ¿Qué le parece? Roa ponderó la oferta. Era una cifra muy grande, pero en realidad no venía siendo gran cosa si se comparaba con el tamaño de la víctima" (279).

El laberinto pareciera cerrarse en la cuarta y última parte llamada "Sombras en las tinieblas". Roa está cada vez más encerrado, acorralado e impotente, y pasa a formar parte de un plan que desconoce. En la oscuridad y sin saber dónde está, se encuentra sentada frente a él la "mano negra", el titiritero que mueve los hilos sin ser visto, el poder sin rostro. Juan Roa es una res rumbo al matadero:

¿Es usted gaitanista?, preguntó la voz. Liberal gaitanista, sí señor, respondió sin vacilar el iluminado. Y siendo gaitanista, prosiguió la voz, ¿está dispuesto a matar a Gaitán? [...] Ya había advertido que esa voz amigable no solo inspiraba confianza, bajo su cuidadosa dicción [...] se revelaba la inocultable insolencia de quien está acostumbrado a mandar y a ser obedecido [...] Sí señor, yo lo mato como sea, yo respondo, exclamó con vehemencia. (319)

Pareciera que Juan Roa había sido convertido a la fuerza en sicario. Pero la novela evade todo tipo de certeza sobre quien apretó el gatillo. Aunque Gaitán cae, se desconoce quién disparó, desde dónde, y por qué. La insistencia del narrador por permanecer en el enigma, en dejar rastros indescifrables de la realidad y preguntas sin responder es una constante hasta las últimas páginas de la novela. La escena del asesinato se presenta difusa e impenetrable. Es una narración llena de sombras y 
atravesada por la duda, pues Roa sólo “alcanzó a distinguir la silueta de un hombre que levantaba el brazo con un objeto reluciente en la mano" (383). El narrador no afirma ni desmiente la autoría de Juan Roa Sierra, un joven de 26 años que sería linchado y arrastrado, y cuyo cuerpo se convertiría en el depósito de la ira popular. En el camino laberíntico emergen figuras como el Flaco, un personaje que ayudará a Juan a navegar entre sus dificultades, sugiriendo por momentos ser un alter ego opuesto de Juan y una escala más en sus desvaríos mentales.

Todos eran sombras, los hombres que lo amenazaron, los empleadores sospechosos y el doctor Urrutia, un "eslabón en la cadena de mando" (245). Pero las preguntas emergen. ¿Para quién trabajaba Urrutia? ¿Para qué trabajo fue contratado Roa? ¿Quiénes amenazaron a Juan? ¿Quién era el Flaco? ¿Era realmente su alter ego?, un tipo que segundos después a los disparos "se lo había tragado la tierra" (383). El narrador deja el misterio intacto, únicamente muestra las fisuras y grietas de un pasado que no deja más remedio que inventarlo. La ruta laberíntica que hace Miguel Torres en las cuatro partes del libro permite componer una sinfonía trágica con predilección por la incertidumbre. Así, "Roa"-primera parte- inicia "la cacería" -segunda parte- para luego caer en "las trampas del azar" -tercera partey terminar confundido por las "sombras en las tinieblas" -cuarta parte-. La invención ficcional de El crimen del siglo propone un pacto de lectura que transita por los pliegues ocultos de la realidad, por lo no dicho y lo no visto como lugares narrativos. Miguel Torres asume la responsabilidad con su tiempo cuando afirma que la ficción histórica es una trinchera que "rescata del olvido hacia la memoria del presente esos acontecimientos, y ofrece la perspectiva de una nueva mirada hacia el pasado". (Torres, Comunicación personal, dic. 2018).

El ocultamiento de El crimen del siglo significa un marcador narrativo que expone una forma de gobierno compuesto por la impunidad y la inmunización del poder como prácticas políticas del Estado. La impunidad, que expresa ausencia de condena, deviene en inmunidad, que denota la exención de la condena. Este marcador se hace visible en indicios que se articulan para mantener a Roa en el misterio. El policía que lo captura le pregunta a Roa: “¿Usted porque asesinó a 
Gaitán?”, a lo que éste responde: “Ay señor. Gime Roa Sierra, yo esas cosas no las puedo decir" (386). Lo cierto es que el veredicto de la justicia sobre el crimen sucedió hasta 1978, tres décadas después del asesinato, cuando el tribunal superior del distrito judicial de Bogotá profirió la sentencia afirmando que "Roa Sierra, el sujeto que lo mató, actuó solo, sin ayuda de nadie, que el planeó y ejecutó el crimen, sin colaboración de ninguna especie, movido por razones esquizomaníacas" (Sánchez 60). Para Miguel Torres señalar a Roa como autor del crimen fue una estrategia para neutralizar investigaciones más exhaustivas y operó como mecanismo de captura de la verdad que impuso un relato sobre el pasado legitimador del presente.

El cuerpo de Roa funcionó como el sacrificio necesario para ocultar a los "verdaderos" culpables a través de la personalización de la figura sacrificial: si la culpa recae en Roa, su cuerpo sin vida permite inmunizar a otros. Junto a la personalización, la despersonalización de la culpabilidad sobre los hechos de la violencia ha sido otra estrategia efectiva para perpetuar la impunidad e inmunizar el statu quo mediante el ocultamiento. Al respecto, Laura Restrepo en su ensayo Niveles de realidad en la literatura de la Violencia en Colombia (1976/2015) llama la atención sobre la función política de la impunidad y la estrategia que hay tras la "designación abstracta" de los culpables y la imposición de la tesis de que "todos somos culpables", lo que equivale a decir que nadie es responsable, y que encubren el verdadero carácter tras la asepsia impersonal de la fatalidad histórica" (Restrepo 453). Dicha tesis se hizo hegemónica tras el asesinato de Gaitán, y fue utilizada con propósitos ideológicos por los distintos gobiernos durante el conflicto armado para "explicar" los acontecimientos y asignar "a la violencia el carácter de una gran Sujeto Histórico trascendente, exterior a los actores del conflicto" (Sánchez 19). El silencio y el ocultamiento como forma de decir es la técnica narrativa de la novela para poner al descubierto la impunidad y la inmunización del poder. 
CATEDRAL TomAda: Revista de crítica literaria latinoamericana / Journal of Latin American Literary Criticism Silencios y repeticiones de la violencia en colombia. La novela histórica como ontología crítica del presente

\section{Tanta sangre vista y las repeticiones de la guerra}

Tanta sangre vista es una novela que, según su autor Rafael Baena, nace como una búsqueda sobre las causas de las guerras en Colombia. Su discurso se refiere a un tiempo nebuloso y un espacio anónimo. Los nombres de ciudades y héroes militares que movilizan la narración son figuras de un tiempo cíclico ficcional que convergen en las guerras del pasado y del presente. Los conflictos narrados entrelazan fenómenos como el secuestro con fines económicos y el surgimiento de ejércitos privados paramilitares que emergieron en las décadas de los 70 y 80 del siglo XX. También se hace referencia a otros problemas, como la lucha por la tierra o las disputas fundacionales en el siglo XIX entre liberales y conservadores por imponer un proyecto de nación. Esta superposición de anacronías tiene como hilo conductor la guerra y la afirmación de la violencia. "Tanta sangre vista es entonces una novela de ficción que actúa como relato distintivo de la que ha sido la constante en la historia colombiana: la guerra y su inacabable derramamiento de sangre" (Montoya 69).

El título de la novela es un enunciado sobre la violencia. La sangre para ser vista debe salir del cuerpo y exponerse. Lo visto son corporalidades que al dejar ver su sangre se convierten en cuerpos heridos. Borges, en el cuento El Otro (1975), subraya que "lo sobrenatural, si ocurre dos veces, deja de ser aterrador" (16), ya que algo excepcional al repetirse entra en el plano de lo corriente. El enunciado borgiano se fija en el título y retumba en la trama narrativa como en la historia del país, pues la sangre derramada ha sido "tanta" que se ha forjado como un hecho constante en el tiempo. El mensaje es reforzado por la fotografía de la portada que muestra a siete militares liberales de Santander durante La Guerra de los Mil Días. Uno de ellos es el general Hermógenes Ordoñez, bisabuelo de Rafael Baena. El recuerdo familiar deviene en rúbrica genética de la memoria bélica del país y en imagen que prefigura el contenido de la novela.

Tanta sangre vista inicia con una guerra y finaliza anunciando la llegada de otra. Aunque la imaginación literaria de Baena recuerda lo improcedente de buscar precisiones o equivalencias entre el texto literario y el discurso histórico, el narrador 
ofrece destellos que permiten ubicar el escenario social e histórico en el turbulento siglo XIX colombiano. La capital, llamada San Pedro del Cerro, es similar a Bogotá, ya que tiene una "catedral con su patrono milagrero, el capitolio nacional en permanente construcción, el palacio presidencial cuyas paredes resanadas ocultan incontables proyectiles de plomo" (127). La permanente disputa bipartidista de esta centuria es aludida en el comportamiento de una sociedad que "estaba acostumbrada a vivir periódicas guerras civiles y conflictos entre los estados de la federación, lo cierto es que desde la guerra de independencia no presenciaba un conflicto de grandes proporciones, como prometía ser este" (61). El no-lugar "real" o atopía narrativa deja huellas que insinúan un posible trayecto histórico que va desde la republica liberal radical (1863-1884), hasta el preámbulo de La Guerra de los Mil Días (1899-1902) (Montoya 69).

La novela narra el acontecer de las batallas alejándose de la representación mimética de los sucesos, optando por acercarse a la experiencia humana del guerrero que se juega la vida en el campo. Tras describir la parafernalia militar del honor y el afán de victoria se da paso al choque de los cuerpos. El personajenarrador observa y comenta que "era una pequeña y sangrienta masacre con vísceras expuestas y miembros amputados, una visión que recomendaría a todos aquellos que se empeñan en encontrarle el lado estético a la guerra sin haber estado jamás en una" (198). La novela indaga por la violencia de un pasado que viaja a caballo por llanuras y montañas, insistiendo que en Colombia las guerras se han elaborado en las ciudades, pero luchado en el campo.

La estructura narrativa se fragmenta en dos épocas que muestran simultáneamente el pasado y el presente del ingeniero y militar liberal Enrique Arce, personaje que relata la historia al compás de sus frustraciones. La primera como un ingeniero civil -una profesión liberal sinónimo del progreso y la civilización- que es arrastrado a batallar y "nunca había podido ejercer por culpa de la maldita política" (46). Más tarde, siendo Mayor del ejército liberal, se enfrenta con el desmoronamiento de las justificaciones políticas o morales de una guerra que parece no terminar. "Los miembros del ejército regular y nosotros peleábamos 
ahora por cosas muy fáciles de explicar y de entender: tierras de cultivo y potreros para el ganado" (12). La argumentación ideológica de la guerra es suprimida cuando percibe que el ejército revolucionario se había convertido en aquello contra lo que luchaba. La revolución triunfó, pero después “el ejército rebelde dejó de ser el defensor de la justicia para convertirse en un monstruo ciego y desordenado que [...] incluso empezó a saquear y a abusar de quienes le habían dado su apoyo" (46). Por último, el ya anciano coronel Arce sufre el secuestro de su hija menor, acontecimiento que lo sume en la melancolía, pues "no se cree capaz de sobrevivir a tanta tristeza" (157). La permanencia de la violencia y la ironía hacia los ideales que alimentaron la voluntad de los que se aventuraron a hacer la guerra son una constante en la novela.

La primera época (mitad del siglo XIX) se refiere al pasado, y se caracteriza por indagar en las causas de la guerra y exponer el creciente escepticismo sobre las justificaciones que la han originado, las cuales van perdiendo valor para Enrique hasta confirmar con el tiempo que ningún conflicto armado favorece a quienes lo pelean. Esta parte es narrada en primera persona por el mayor del ejército liberal Enrique Arce, quien comanda el "Cuarto de lanceros", un grupo de campesinos que han dejado sus familias para servir a causas ajenas. En sus inicios, el Mayor abrazó la causa liberal como medio para modernizar y desarrollar a una sociedad dominada por costumbres heredadas de la colonia y defendida por la oligarquía conservadora. Sin embargo, va advirtiendo cómo la élite, liberal o conservadora, instrumentaliza los ideales y utiliza la guerra para sacar beneficios personales mediante "matices que los políticos, los comerciantes y los leguleyos fueron introduciéndoles a unos ideales que ya no lo eran" (12). El desmoronamiento de la causa justa que lo movilizó al inicio lo lleva a reconocer la inutilidad de la guerra y a cuestionar el uso de la vida de los guerreros. Mientras Enrique observa a sus subalternos se pregunta: “¿Por qué carajos peleaban?” (23).

La verdad es que peleaban por costumbre, porque no sabían hacer nada más, porque a lo mejor tanta sangre vista y tanto retumbar de cañón les 
habían aturdido las entendederas, lo cual explicaba ese aire de orfandad común a la mayoría, esas miradas que siempre parecían fijas en algún punto más allá de la realidad, de su realidad, que era la de todos nosotros, fantasmas de otros tiempos condenados a cabalgar con las casacas remendadas y los sables amenazados por el colapso del orín. (24)

Se produce en Enrique una dislocación de la realidad para ver la guerra como lo que es, "una molestia ineludible e inaplazable, no una profesión, y mucho menos una forma de vida" (125). Junto con el Mayor destaca la presencia del sargento Gregorio Medina, un viejo que había perdido un ojo luchando en las guerras de independencia. Tras quedar cojo de por vida, el cuerpo cansado y lisiado de Enrique posiciona el modo de subjetivación que produce la guerra en quien la ha vivido: el rechazo de su utilidad de las justificaciones de hacerla. Este mensaje se advertirá recurrente en otras novelas que versan sobre la guerra, como por ejemplo Homenaje a Catalunya escrita por George Orwell. Al mismo tiempo, Baena insiste en mostrar la guerra como manera de hacer política, lo que convierte al espíritu bélico en un mecanismo de gobierno y una forma particular de biopolítica (Pérez 37-40) cuya inscripción se funde en los cuerpos mutilados y lesionados como el de Medina o Arce. El narrador expone su experiencia y observa sofocado aquello que vive:

Era la misma jodida guerra de siempre, con los mismos generales, los mismos oficiales con las mismas casacas [...] uno pensaría, los mismos campesinos de siempre morían por las mismas razones de siempre. Solo que no eran los mismos, aunque lo parecieran. La cuota de carne de cañón se elevaba en la medida en que pasaban los años y la guerra no cesaba. (119)

La segunda época se ubica en el presente (preludio de La Guerra de los Mil Días), habla del veterano coronel Enrique Arce y se narra en tercera persona. Junto 
con Enrique emerge su nieto Ricardo, quien además de caer en el torbellino de nuevas guerras que se anuncian, aparece como un retorno del viejo en la época de su juventud, pues eran "dos gotas de agua, salvo por la diferencia de edades" (237). La vorágine de la violencia se pretende refrendar en la experiencia del joven. Esa transposición de la experiencia que pasa del abuelo al nieto erosiona la subjetividad de cada uno y hace que las violencias sean vistas de nuevo con otros ojos y desde otros rostros. Antes fue Enrique quien vio sangre y ahora es el turno de Ricardo; eso es lo que agobia y no deja en paz al viejo. Los dos extremos del tiempo se tocan y como la serpiente del Uróboro que muerde su cola, abuelo y nieto anuncian el retorno de un pasado que "sigue siendo" (Ainsa 15).

Enrique representa al patriarca ilustrado y terrateniente latinoamericano que piensa que los "hombres" deben vivir en el campo y alimentarse de la tierra, por lo que desconfía de la sociedad citadina y el "afeminamiento de sus costumbres" (Montoya 71). Como manda la costumbre, ha formado una familia y, mientras sus hijos han tomado la decisión "civilizada" de hacer sus vidas en la ciudad, él se mantiene en su hacienda con su esposa Camila. El significado que lleva consigo Enrique Arce denota el modelo de nación heteronormativa, patriarcal, con identidad homogénea y patrimonialista que delinearon las élites latinoamericanas en el ensamblaje del Estado-nacional durante el siglo XIX. De otra parte, el héroe que encarna Arce es un proyecto fallido y un ejemplo de la "falibilidad heroica" (Fuentes xvi), a través de la macula de la guerra que permanece en su memoria. "Se trata de una familia urgida de sumergir el pasado en el lago de la amnesia" (16). El viejo veterano pasa los días perseguido por su pasado: "Enrique habla y habla, en parte por el gusto de hacerlo, en parte como forma de exorcizar aquellos demonios del pasado que no le dejan volver a conciliar el sueño después de la meada de las tres de la madrugada" (15).

El retorno de la violencia que enfrenta el viejo coronel Arce ya no se da por las diferencias partidistas, sino por el secuestro de su hija menor con fines económicos. El secuestro va a ser una práctica de violencia desarrollada y sofisticada durante el Conflicto Armado, principalmente desde las décadas de los 
70 y 80 del siglo XX. En la novela, esta práctica anacrónica surge como consecuencia de las guerras anteriores, ejecutada por cuerpos errantes que hicieron de las polainas, la espada y la carabina su forma de vida. La explicación acerca de los autores del secuestro desnuda las falacias de las justificaciones ideológicas, ya que el cobro de recompensa por el rescate es la demanda de una transacción que devela el fracaso del proyecto modernizador. El secuestro se afirma como la herencia de una pacificación excluyente, un pacto de "caballeros" del que la familia Arce fue beneficiaria cuando se firmaron los tratados de paz, cuyos abismos y fracturas sociales regresan para recordar que los guerreros rasos utilizados por los dirigentes de los partidos para hacer sus guerras son deudas pendientes de la "institucionalidad republicana”. Enrique se pregunta: “¿Quién se llevó a Merceditas?"

Ha sido una de las bandas de merodeadores de la llanura, le explica Camila, veteranos de todos los bandos que jamás dejaron las armas y no conocen otra forma de sobrevivir distinta a la vieja costumbre de apoderarse de los bienes del vencido. $\mathrm{Y}$ ahora no entienden que lo suyo no es más que simple saqueo, extorsión a mano armada y, en este caso, secuestro de una persona a cambio de dinero. La banda está conformada por un tal Bonilla, antiguo guerrillero que primero fue radical, luego soldado federal. (103)

Su hija Merceditas es asesinada, lo que despierta el deseo de venganza de la familia Arce e inocula el miedo en otros terratenientes. Para garantizar la seguridad surge la privatización de la justicia mediante la conformación de ejércitos privados conformados por campesinos desocupados, e incluso por "oficiales del ejército cansados de la mala paga y de esperar la oportunidad de lograr un ascenso al son de los tambores de batalla" (288). Resuena el eco de la tesis del "Estado fallido" o el "derrumbe parcial del Estado" (Sánchez 29) incapaz de garantizar la seguridad y el respeto de la propiedad privada. El para-ejército será una "reacción 
de los lugareños ante los abusos de los señores de la guerra” (288). Se crea un "estado mayor en la sombra, integrado por empresarios y hacendados que aportan fondos para la compra de armas y para la soldada de la tropa” (289). Su presencia tiene impactos inmediatos y "en los torrentes de los ríos comienzan a aparecer cadáveres de antiguos guerrilleros, bandoleros de todas las pelambres, ladrones de ganado y en general hombres que no habían conseguido abandonar las armas como modo de vida" (290).

La anacronía termina de tomar forma con el nombre que recibe el ejército privado, "los doce sacerdotes de Némesis" (290) y que solapa el de "los doce apóstoles", un grupo paramilitar que entre 1992 y 1994 azotó el departamento de Antioquia. Sobre este hecho, destaca la investigación de la periodista y escritora Olga Behar publicada en el libro El clan de los doce apóstoles (2011), obra que devela múltiples tramas criminales auspiciadas por la fuerza pública. En el año 2016 Santiago Uribe Vélez, hermano del expresidente Álvaro Uribe Vélez es detenido y acusado de ser el arquitecto y comandante de este grupo armado. En 2018 recobró su libertad, aunque a día de hoy el proceso sigue abierto. Esta pista da cuenta de la significación que tienen las condiciones de producción en las modulaciones discursivas de la obra. El signo de este suceso en la novela proyecta el mundo degradado del hacendado ilustrado Enrique Arce y le propina el golpe fulminante al héroe vencido y al Estado fallido. En las páginas finales el presagio es telúrico: "Lo que se avecina es la guerra civil, de nuevo la larga noche de la incertidumbre, el reinado de las charreteras, las botas altas y el afán de comprobar quien tiene mejor ajustada la bragueta del pantalón. En suma, otra vez la estupidez de la guerra entre hermanos" (313).

Como Teseo, Enrique Arce lleva consigo un hilo rojo que lo dirige hacia una salida ilusoria y que lo retorna de nuevo al centro del laberinto. En este caso, el hilo es la guerra, la salida es un nuevo comienzo de la nueva confrontación bélica, y Enrique la imagen de un héroe que encarna el fracaso del relato ilustrado de la nación. La permanencia de la guerra en la historia de Colombia, que en principio fue leída desde una perspectiva patológica (Fals Borda T.II 483), ha sido abordada 
desde enfoques que reconocen la confrontación como la forjadora de los significados en el proceso de nacionalización (González 193-195) emanado de las elites. En este sentido, las guerras del siglo XIX configuraron la gramática ilustrada de la nación, pues eran conflictos "entre ciudadanos" (Uribe de Hincapíe 29). El ciudadano blanco, letrado y propietario ubica a Enrique Arce como un exponente trágico de aquella élite que posicionó la guerra como forma normalizada de hacer política. En la tradición política colombiana, el acontecimiento político que debía propiciar la construcción social de un proyecto histórico incluyente ha sido una perturbación y una excepción al ordenamiento institucional.

De acuerdo con esto, la guerra deviene en un dispositivo de gobierno registrado, no como una permanente confrontación, sino como la movilización de un "animus belli", una figura de "la voluntad manifiesta e indeclinable de no someterse a la autoridad instituida y de no aceptar un poder distinto al propio" (Uribe de Hincapié 11). El "animus belli" trazado por las élites liberales y conservadoras durante el siglo XIX fue la norma en el establecimiento del imaginario de la acción/nación política. Este dispositivo de guerra muestra otra forma de inmunización del poder narrada en Tanta sangre vista, una paradoja que pone de manifiesto que "el relato trágico cumplía la tarea de anudar el pasado con el presente y de darle continuidad y permanencia a la nación" (21).

\section{Conclusiones: la novela y la ontología crítica del presente}

Todo ejercicio hermenéutico reconoce que la lectura de una obra literaria es siempre inacabada e incompleta, ya que leer es capturar, configurar e imaginar un sentido posible entre el universo de sentidos que contiene la obra (Garrido 103). Esta premisa lleva a aceptar los límites del presente trabajo y proponer un horizonte de sentido mediante el uso de la ontología crítica y el reconocimiento de la dimensión política de la creación literaria. De esta forma, se asume que la escritura -de la obra literaria- es una experiencia de autoconstitución de subjetividad, una hermenéutica de sí y una práctica de libertad en continua relación con los demás. Es, en este sentido, un asunto ético y político que deviene en praxis comunicativa, 
ya que "la práctica de uno mismo implica por tanto una nueva ética de la relación verbal con el otro" (Foucault Hermenéutica 50). Las anteriores aclaraciones permiten dar paso a algunas ideas y reflexiones surgidas en el proceso de análisis de los discursos novelescos.

Las novelas se distancian de hacer una confrontación a la validez del relato histórico "oficial" para, en cambio, configurar una analítica estética de las condiciones de posibilidad de su producción, pues además de recrear el pasado ofrecen herramientas para reflexionar sobre la naturalización del presente. En vez de buscar en sus discursos señalamientos, exclusiones y contradicciones en el proyecto republicano expuesto por la historiografía monumental, los autores se interesan por examinar poética y ficcionalmente la cartografía del pasado, con el fin de "participar en la lucha por su significado" (Castro Gómez 256) en la actualidad. Es ahí donde reside el potencial de la perspectiva ontológica aplicada a la obra literaria, cuyo interés, en vez de destruir las políticas de verdad que subyacen en la Historia, pretende desnudar su fragilidad e inestabilidad. Este tipo de lectura aplicado a la literatura de ficción ofrece múltiples sentidos y posibilidades de apertura de aquella totalidad/realidad que se presenta como inevitable y sedimentada.

Resulta relevante el papel de las anacronías en la crítica a la solidez identitaria de la comunidad nacional y del proceso modernizador. A través de los marcadores narrativos identificados en las novelas se observan formas de inmunización del poder que históricamente ha operado como reproductoras del orden institucional. Estos mecanismos inmunitarios han proyectado la imagen de un país con una longeva tradición civilista y democrática en América Latina. En ambas novelas se ironiza esta supuesta estabilidad, con el propósito de manifestar que las marcas de la guerra y el conflicto han configurado un ethos gatopardista como motor de la razón de Estado en Colombia. Los "ocultamientos y silencios" en El crimen del siglo y las "repeticiones" de la guerra en Tanta sangre vista promueven la invención de lo acontecido como un acto de trasgresión. Estos marcadores son también un gesto de complicidad que recuerda a Pilar Ternera en 
Cien años de soledad "cuando concibió el artificio de leer el pasado en las barajas como antes había leído el futuro" (45). Adivinar e inventar el pasado -y no el futuro- para examinar el presente como oficio del prestidigitador es, para la narrativa histórica, una manera de resquebrajar la inmunidad del poder establecido en la actualidad.

Los proyectos narrativos del pasado que formulan las novelas sugieren que los mecanismos de inmunización del poder en Colombia se han sostenido sobre experiencias de impunidad. Si la inmunidad es la exención de la condena y configura un vacío de significado frente a la responsabilidad, la impunidad -en tanto ausencia de condena- convierte a la idea de justicia en un significante colectivo degradado, falso y violento. Este modo reaccionario de ejercer la memoria en Colombia ha fomentado la normalización de la violencia. En este sentido, la literatura encara el problema observando por las rendijas y las grietas de lo indecible, con el fin de mostrar la dimensión abismal y el vacío constitutivo de la imagen nacional. Miguel Torres se pregunta por qué "paradójicamente la gente no quiere saber nada de eso", mientras que Rafael Baena sentencia que la guerra de hoy ya ha sucedido.

La representación de la violencia expuesta en las novelas está inscrita en los cuerpos de Juan Roa y Enrique Arce como "versiones" de la nación. Son cuerpos de "héroes fallidos" y subjetividades resultantes del proceso de nacionalización; protagonistas de novelas surgidas durante un periodo caracterizado por el escalamiento de la violencia provocada por el Conflicto Armado. El horizonte romántico del héroe es desplazado por el horizonte patriótico de la nación encarnado en dichos personajes. La fragilidad ontológica de Juan Roa y la melancolía de Enrique Arce ofrecen una relación especular con una sociedad que tiene la oportunidad histórica de edificar procesos de memoria histórica en la etapa del pos-acuerdo. A su vez, las condiciones de producción de las novelas se ubican en un periodo del Conflicto Armado sumergido por prácticas de violencia desgarradoras. Entre el 2002-2010 los "falsos positivos" o las ejecuciones extrajudiciales sumaron más de 10.000 personas no combatientes asesinadas por 
militares (Rojas 49-66) y el Centro Nacional de Memoria Histórica documentó un total de 402 masacres en el periodo mencionado.

La comprensión del oficio de autor como una experiencia vital/corporal, vinculada a los pliegues de sentido de la actualidad, ofrece marcos analíticos clave para pensar el campo artístico y cultural en un registro emancipatorio. Para Nietzsche, el vacío y lo incierto es lo propio del arte, pues penetra en los cimientos de la razón moderna y devela su inherente debilidad: la obsesión por erradicar el conflicto y el antagonismo. Tal vez lo que ha convocado a Torres y Baena, además de la permanencia y el silenciamiento de los conflictos y las violencias a lo largo de la historia compartida, es la mezquina y equivocada actitud de negarlos, de mirarlos con indiferencia y de no querer saber nada.

\section{Bibliografía}

Aínsa, Fernando. Ensayos. Mérida: Ediciones El otro, el mismo, 2014.

Baena, Rafael. Tanta sangre vista. Bogotá: Alfaguara, 2007. . "Lecturas críticas de Rafael Baena". Periódico de libros [Entrevista].

Dir. Carlos Andrés Almeyda. 17 agosto 2010. https://www.youtube.com/watch?v=F1cDL5vRbVs . "Olvidar no se puede, perdonar sí". Fundación razón Pública [Entrevista]. Enero 2014. https://www.youtube.com/watch?v=HE2x_AxcPZM

Butler, Judith. Dar cuenta se sí. Violencia, ética y responsabilidad. Buenos Aires: Amorrotú, 2009.

Fals Borda, Orlando, Et al. La Violencia en Colombia. Tomos I y II. Bogotá: Punto de Lectura, 1962/2010.

Borges, Jorge Luís. “Coloquio”. Literatura fantástica. Madrid. Ediciones Siruela. pp. 13-36, 1985.

Cadahia, María Luciana. "Dispositivos estéticos y formas sensibles de la emancipación”. Ideas y Valores 65.161 (2016): 267-285.

Cartagena Núñez, Catalina. "Marcos narrativos y emergentes contra-narrativos de la violencia en Colombia”. Humanidades Vol. 5, Núm 1 (2015): pp. 331.

Castro-Gómez, Santiago. Crítica de la Razón Latinoamericana. Bogotá: Editorial Pontificia Universidad Javeriana. Instituto Pensar, 1996/2011. 
Foucault, Michel (1979). Microfísica del poder. Madrid: Ediciones de la Piqueta, 1979.

. Saber y verdad. Madrid: Ediciones de la Piqueta, 1991 . Hermenéutica del Sujeto. Madrid: Ediciones de la Piqueta, 1994.

García Márquez, Gabriel. Cien años de soledad. Bogotá: Editorial La Oveja Negra, 1967/1979.

Garrido, Antonio. "El texto literario a la luz de la Hermenéutica". Revista SIGNA, núm. 13, (2004): pp. 103-124.

Gómez Valderrama, Pedro. "El trabajo literario". Ensayos sobre literatura colombiana y latinoamericana. Comp. Unión Nacional de Escritores.

Bogotá: Fondo Promoción de la Cultura del Banco Popular, 1989.

González, Fernán, Et al. Violencia política en Colombia. De la nación fragmentada a la construcción del Estado. Bogotá: Centro de Investigación y Educación Popular - CINEP, 2003.

Lukács, Georg. La novela histórica. Ciudad de México: Grijalbo. 1954/1975.

Mártinez, Jorge, Et al. [Comps.] Miradas sobre la subjetividad. Bogotá: Universidad de La Salle, 2009.

Menton, Seymour. La nueva novela histórica de la América Latina, 1979- 1992. México: Fondo de Cultura Económica, 1993.

Montoya, Pablo. La novela histórica en Colombia: 1988-2008. Entre la pompa y el fracaso. Medellín: Universidad de Antioquia, 2009.

Osorio, Óscar. "Siete estudios sobre la novela de la Violencial en Colombia, una evaluación crítica y una nueva perspectiva”. Revista Poligramas, núm 25, (2006): pp. 85-108.

Pérez González, Bibiana. "Biopolítica e Imperio: Modos de subjetivación en Colombia frente al dispositivo biopolítico de la guerra". Tesis de doctorado. Universidad de Valencia, 2017.

Restrepo, Laura. "Niveles de realidad en la literatura de la Violencia en Colombia". Antología del pensamiento crítico colombiano contemporáneo. Comp. Víctor Manuel Moncayo. Buenos Aires: CLACSO, 1976/2015.

Rojas Bolaños, Omar, Et al. Ejecuciones extrajudiciales en Colombia, 2002-2010 Obediencia ciega en campos de batalla ficticios. Bogotá: Ediciones Universidad Santo Tomás, 2017.

Rosset, Clement. Lo real y su doble. Ensayo sobre la ilusión. Barcelona: Tusquests editores, 1993.

Sánchez, Gonzalo, Et al. [Comps.]. Pasado y presente de la violencia en Colombia. Medellín: La carreta, 1986/2015.

Sánchez, Carlos A. "La decisión judicial sobre la muerte de Gaitán”. Estudios Socio-Jurídicos, [S.1.], v. 3, n. 1, (2001): pp. 60-92.

Torras, Meri. "Y el verbo se hizo carne. Vías de encarnación de un corpus-cuerpo autorial". Estudios 21:42, (2013): pp. 23-41.

Torres, Miguel. El Crimen Del Siglo. Bogotá: Editorial Alfaguara, 2006 . Comunicación personal. Archivo personal, diciembre. 2018. 
. "Breve historia de un amor sin fin". 6to Festival de Literatura Oiga, Mire, Lea. [Entrevista]. 2 septiembre 2020.

https://www.youtube.com/watch?v=xTsjTRZTKW0

Uribe de Hincapié, María T. "Las guerras por la nación en Colombia durante el siglo XIX. Estudios Políticos, (18), (1991): pp. 9-27.

Zuleta, Mónica. La voluntad de verdad en Colombia: una genealogía de las ciencias sociales profesionales. Bogotá: Universidad Central. Instituto de Estudios Sociales Contemporáneos - IESCO, 2011. 